\title{
Exercise-Induced Fatigue in Severe Hypoxia Following an Intermittent Hypoxic Protocol
}

Rosie Twomey ${ }^{1,2}$, James Wrightson ${ }^{2}$, Hannah Fletcher ${ }^{2}$, Stephanie Avraam ${ }^{2}$, Emma Ross ${ }^{3}$, and Jeanne Dekerle ${ }^{2}$

${ }^{1}$ Human Performance Laboratory, Faculty of Kinesiology, University of Calgary, Calgary, AB, Canada; ${ }^{2}$ Centre for Sport and Exercise Science and Medicine, University of Brighton,

Eastbourne, United Kingdom; ${ }^{3}$ English Institute of Sport, Bisham Abbey National Sports Centre, Marlow, United Kingdom

\section{Corresponding author:}

Dr Rosie Twomey, PhD

Human Performance Laboratory, Faculty of Kinesiology

University of Calgary, 2500 University Drive NW

Calgary, Alberta, T2N 1N4 (Canada)

Phone: + 1 (403) 220-2170.

Fax: +1 (403) 220-0448.

E-mail: rosemary.twomey@ucalgary.ca 
No conflicts of interest, financial or otherwise, are declared by the authors. The authors declare that the results of the study are presented clearly, honestly, and without fabrication, falsification, or inappropriate data manipulation. The results of the present study do not constitute endorsement by the American College of Sports Medicine. 


\section{ABSTRACT}

Purpose: Exercise-induced central fatigue is alleviated following acclimatisation to high altitude. The adaptations underpinning this effect may also be induced with brief, repeated exposures to severe hypoxia. The purpose of this study was to determine whether (i) exercise tolerance in severe hypoxia would be improved following an intermittent hypoxic (IH) protocol and (ii) exercise-induced central fatigue would be alleviated following an IH protocol. Methods: Nineteen recreationally-active males were randomised into two groups who completed ten 2-h exposures in severe hypoxia $\left(\mathrm{IH}: \mathrm{P}_{\mathrm{I}} \mathrm{O}_{2} 82 \mathrm{mmHg} ; n=11\right)$ or normoxia (control; $\left.n=8\right)$. Seven sessions involved cycling for $30 \mathrm{~min}$ at $25 \%$ peak power ( $\left.\dot{W}_{\text {peak }}\right)$ in $\mathrm{IH}$, and at a matched heart rate in normoxia. Participants performed baseline constant-power cycling to task failure in severe hypoxia $\left(\mathrm{TTF}_{-\mathrm{Pre}}\right)$. After the intervention, the cycling trial was repeated $\left(\mathrm{TTF}_{\text {-Post }}\right)$. Pre- and postexercise, responses to transcranial magnetic stimulation and supramaximal femoral nerve stimulation were obtained to assess central and peripheral contributions to neuromuscular fatigue. Results: From pre- to post-exercise in TTF-Pre, maximal voluntary force (MVC), cortical voluntary activation $\left(\mathrm{VA}_{\mathrm{TMS}}\right)$ and potentiated twitch force $\left(\mathrm{Q}_{\mathrm{tw}, \mathrm{pot}}\right)$ decreased in both groups (all $p<0.05)$. Following IH, TTF-Post was improved $(535 \pm 213 \mathrm{~s}$ vs. $713 \pm 271 \mathrm{~s}, p<0.05)$ and an additional isotime trial was performed. After the IH intervention only, the reduction in MVC and $\mathrm{VA}_{\mathrm{TMS}}$ was attenuated at isotime $(p<0.05)$. No differences were observed in the control group.

Conclusion: Whole-body exercise tolerance in severe hypoxia was prolonged following a protocol of IH. This may be related to an alleviation of the central contribution to neuromuscular fatigue. 


$$
\text { (4) }
$$




\section{INTRODUCTION}

Whole-body exercise tolerance in severe acute hypoxia $(\mathrm{AH})$ is markedly impaired $(4,14)$. The reduction in exercise tolerance in $\mathrm{AH}$ is not only a concern for mountaineers, but also military forces, where tactical necessity can result in rapid ascent of service personnel to high altitude and result in debilitating reductions in physical operational capabilities (28). At task failure following constant-power cycling in $\mathrm{AH}$, neuromuscular fatigue is evident as a reduction in the ability to produce maximal isometric force, with a clear central contribution $(4,17,19)$. Studies utilizing transcranial magnetic stimulation (TMS) before and after a fatiguing motor task in $\mathrm{AH}$ have shown that at least some of the resulting loss of force originates at or upstream of the motor cortex $(17,19,36)$. This decrease in cortical voluntary activation $\left(\mathrm{VA}_{\mathrm{TMS}}\right)$ occurs alongside pronounced cerebral deoxygenation and as such, exercise in $\mathrm{AH}$ is considered to be limited primarily by the hypoxic central nervous system (CNS) $(11,47)$. Further evidence for this is provided from studies using an increase in the partial pressure of inspired $\mathrm{O}_{2}\left(\mathrm{P}_{\mathrm{I}} \mathrm{O}_{2}\right)$ at volitional exhaustion, where the capacity to resume whole-body exercise occurs too rapidly to be due to a reversal of metabolic disturbance in the locomotor muscles (e.g. (4)).

Initial evidence suggests that the mechanisms of exercise-induced fatigue in $\mathrm{AH}$ can be modulated by the physiological adaptations associated with acclimatization $(3,19)$. A 14-day exposure to high altitude $\left(\mathrm{P}_{1} \mathrm{O}_{2} 76 \mathrm{mmHg}\right)$ alleviated exercise-induced central fatigue and this occurred alongside improvement in indices of systemic and cerebral $\mathrm{O}_{2}$ availability $(3,19)$. However, chronic exposure to hypoxia involves substantial logistical demand, immunological consequences (27), and risk of acute mountain sickness (AMS) (15). As such, intermittent 
hypoxia (repeated exposures to sustained hypoxia lasting minutes to hours) via a decrease in $\mathrm{P}_{\mathrm{I}} \mathrm{O}_{2}$, has been investigated as a means of promoting physiological adaptations without a prolonged stay at high altitude (or confinement to a hypoxic chamber) (28).

Following acclimatisation, a number of mechanisms may be responsible for an improved exercise tolerance in severe hypoxia (41). Hemoglobin concentration $[\mathrm{Hb}]$ is higher due to a reduction in plasma volume, and $\mathrm{O}_{2}$ carrying capacity is improved via erythropoiesis (measured as an increase in total hemoglobin mass (37); Hbmass). Furthermore, hemoglobin saturation $\left(\mathrm{S}_{\mathrm{p}} \mathrm{O}_{2}\right)$ is increased during hypoxic exercise (3). These mechanisms contribute to an increase in arterial $\mathrm{O}_{2}$ content $\left(\mathrm{C}_{\mathrm{a}} \mathrm{O}_{2}\right)$ during constant-power cycling in chronic hypoxia in comparison to AH (3). However, it is not necessarily the systemic improvement in $\mathrm{C}_{\mathrm{a}} \mathrm{O}_{2}$ that results in an alleviation of central fatigue in chronic hypoxia, but may be the resulting improvement in cerebral $\mathrm{O}_{2}$ delivery $\left(\mathrm{CDO}_{2}\right)(19) . \mathrm{C}^{\circ} \mathrm{O}_{2}$ may be improved in the face of an unchanged cerebral blood flow (CBF), where $\mathrm{CBF}$ is subject to the opposing influences of hypocapnia-induced cerebral vasoconstriction (via hyperventilation) and hypoxia-induced cerebral vasodilation (1).

At least some of the adaptations that compensate for a reduced $\mathrm{P}_{\mathrm{I}} \mathrm{O}_{2}$ in chronic hypoxia may be achievable with an IH protocol. The principal beneficial response to IH that mimics acclimatization is considered to be an increase in $\mathrm{C}_{\mathrm{a}} \mathrm{O}_{2}$ via early respiratory changes related to an increase in hypoxic chemosensitivity $(7,10,28)$. In contrast, the evidence is largely unsupportive of an increase in $[\mathrm{Hb}]$ or Hbmass with $\mathrm{IH}$ protocols (26), likely due to an insufficient total duration of hypoxic exposure (32). However, alterations are more rapid in severe hypoxia (37), and may be possible with an IH protocol involving exercise training (34). 
Few studies have investigated exercise tolerance in severe hypoxia following IH protocols conducted at the same $\mathrm{P}_{1} \mathrm{O}_{2}$, and some have shown improvements in whole-body exercise tolerance in the severe-intensity domain (e.g. $(5,7))$. However, neither of these examples included a control group. To our knowledge, no study has investigated central and peripheral fatigue following an IH intervention. Therefore, the aims of this study were to determine whether (i) exercise tolerance in severe hypoxia could be improved following an IH protocol in comparison to a control protocol in normoxia and (ii) exercise-induced central fatigue would be alleviated following an IH protocol. It was hypothesised that (i) an IH protocol would result in an improvement in exercise tolerance in severe hypoxia and (ii) the central contribution to neuromuscular fatigue would be alleviated following an $\mathrm{IH}$ protocol.

\section{METHODS}

\section{Participants}

Twenty-one participants were fully informed of the procedures and risks involved and provided written consent to participate. All participants were male, non-smokers, free from contraindications to experimental procedures including any history of cardiorespiratory or neurological disease, lowlanders, and had not visited altitudes $\geq 1000 \mathrm{~m}$ in the 3 months preceding the study. Participants were regularly physically active at a recreational level and were instructed to refrain from strenuous training for the duration of the experimental protocol. Participants were matched for normoxic peak $\mathrm{O}_{2}$ uptake $\left(\dot{V}_{2 \text { peak }}\right)$ and randomly assigned (GraphPad Software Inc, USA) to one of two treatment groups: IH or control. Nineteen participants completed all trials (IH: $n=11, \dot{V} \mathrm{O}_{2 \text { peak }} 3.32 \pm 0.42 \mathrm{~L} \cdot \mathrm{min}^{-1}$, age $23 \pm 2$ years, height $180 \pm 6 \mathrm{~cm}$, body mass $76.4 \pm 13.7 \mathrm{~kg}$; and control: $n=8,3.48 \pm 0.36 \mathrm{~L} \cdot \mathrm{min}^{-1}, 22 \pm 4$ years, 180 
$\pm 6 \mathrm{~cm}, 83.0 \pm 5.5 \mathrm{~kg}$ ). The study was approved by the university research ethics committee and was performed according to the Declaration of Helsinki.

\section{Experimental Design}

For each participant, all testing was performed at the same time of day $\pm 1 \mathrm{~h}$. Over two familiarization visits, participants were accustomed to (i) the neuromuscular assessment and cycle ergometer, and (ii), the optimised carbon monoxide rebreathing (oCOr) method (Figure 1A). On a third visit, $\dot{V} \mathrm{O}_{2 \text { peak }}$ was obtained from a normoxic incremental cycling test $\left(5 \mathrm{~W} \cdot 12 \mathrm{~s}^{-1}\right.$ from $80 \mathrm{~W}$, preceded by a 3 -min prior exercise at $50 \mathrm{~W})$. Peak power $\left(\dot{W}_{\text {peak }}\right)$ was derived as the highest power averaged over $30 \mathrm{~s}(\mathrm{IH}: 309 \pm 23$; control: $313 \pm 20 \mathrm{~W}$ ). All subsequent cycling trials and both interventions were performed inside a large, purpose-built chamber (The Altitude Centre, UK; ambient temperature $19 \pm 1^{\circ} \mathrm{C}$, relative humidly $40 \pm 2 \%$, barometric pressure $760 \pm$ $2 \mathrm{mmHg}$ ). Normobaric, poikilocapnic hypoxia was delivered and maintained at a $\mathrm{P}_{\mathrm{I}} \mathrm{O}_{2}$ of $82 \pm 1$ $\mathrm{mm} \mathrm{Hg}$ via nitrogen enrichment (equivalent to $\sim 4700 \mathrm{~m}$ above sea level).

All participants performed a constant-power cycling trial to task failure (TTF) before the intervention ( $\geq 48 \mathrm{~h}$ after the incremental exercise test) and after the intervention (48 $\mathrm{h}$ after the final exposure). The pre-intervention TTF is referred to as TTF-Pre. Following the intervention, there was no significant change in the performance of the control group (see Results section). As such, the post-intervention TTF was treated as an 'isotime' trial (ISO). In the IH group, there was a significant increase in TTF post-intervention (TTF-Post). The IH group performed an additional isotime trial $\left(\mathrm{ISO}=\mathrm{TTF}_{\text {-Pre }}\right) 48 \mathrm{~h}$ after $\mathrm{TTF}_{\text {-post. }}$ Total $\mathrm{Hb}$ mass was measured before the intervention and $72 \mathrm{~h}$ after the final exposure. 


\section{The Intervention}

Over $14 \pm 2$ days, participants in the IH group performed 10 hypoxic exposures of 2-h duration. The control group completed an identical protocol in normoxia $\left(\mathrm{P}_{\mathrm{I}} \mathrm{O}_{2} 149 \pm 1 \mathrm{mmHg}\right)$. During exposure 1, 5 and 10, participants remained seated for $2 \mathrm{~h}$. During the remaining sessions, participants undergoing $\mathrm{IH}$ were seated for $90 \mathrm{~min}$ and cycled for $30 \mathrm{~min}$ at $25 \% \dot{W}_{\text {peak }}$. During the first exercise bout in the control group, the power was adjusted to produce the same heart rate (HR) as for the IH group $\left(131 \mathrm{~b} \cdot \mathrm{min}^{-1}\right)$. This power was fixed for the remaining exercise bouts $\left(38 \pm 2 \% \dot{W}_{\text {peak }}\right)$. Arterial $\mathrm{O}_{2}$ saturation was estimated using a pulse oximeter $\left(\mathrm{S}_{\mathrm{p}} \mathrm{O}_{2}\right)$ with a fingertip sensor placed on the participant's right index finger (PalmSAT 2500 and 8000AA, Nonin Medical Inc, Minnesota, USA). HR (Polar Electro, Tampere, Finland) and $\mathrm{S}_{\mathrm{p}} \mathrm{O}_{2}$ were recorded at 10-min intervals at rest, and 5-min intervals during exercise. Symptoms of AMS were assessed at 10-min intervals using the Lake Louise Questionnaire (LLQ) (33), with the sleep questions removed.

During the intervention, participants were naïve to the aims of the study and blinded to the $\mathrm{O}_{2}$ levels inside the chamber, their $\mathrm{HR}, \mathrm{S}_{\mathrm{p}} \mathrm{O}_{2}$ and power during cycling. To assess the blinding procedures after completion of the final visit, participants were asked to complete a brief questionnaire to indicate whether (i) their exposures were in 'severe hypoxia (more than $4000 \mathrm{~m}$ above sea level)' or 'normoxia (sea level)', and (ii) if they were 'certain', 'fairly sure' or 'uncertain' about their answer. In response to (i), 53\% of participants answered correctly and in response to (ii), $74 \%$ indicated that they were 'uncertain' about their answer. 


\section{Total Hemoglobin Mass}

The oCOr was used to derive Hbmass, blood volume and plasma volume (38). A detailed description of the equipment and specific methods used has previously been described (45). Testretest reliability was evaluated prior to the study with eight recreationally-active males (Hbmass: CV 3.9\%, ICC 0.94, TEM 36 g; plasma volume: CV 3.3\%, ICC 0.92, TEM 43 mL; blood volume: CV 3.1\%, ICC 0.94, TEM $66 \mathrm{~mL}$ ).

\section{Constant-Power Cycling Trials}

Upon arrival to the laboratory, participants provided a mid-stream urine specimen. Euhydration was accepted as a urine specific gravity of $<1.020$ g. $\mathrm{mL}^{-1}$ and osmolality $<700$ mOsmols. $\mathrm{kgH}_{2} \mathrm{O}^{-1}$. Following $3 \mathrm{~min}$ at $50 \mathrm{~W}$, power output was increased to $60 \% \dot{W}_{\text {peak }}$ (IH: 187 $\pm 14 \mathrm{~W}$; control: $188 \pm 12 \mathrm{~W}$ ). Trials were performed on an electromagnetically-braked cycle ergometer (SRM High Performance Ergometer; Schroberer Rad Meßtechnik, Jülich, Germany) with body position and self-selected cadence determined during familiarization, and replicated for the duration of the study. Cadence $\left(87 \pm 4 \mathrm{rev} \cdot \mathrm{min}^{-1}\right)$ was the only real-time feedback participants received and verbal instructions were given should participants drift by $\geq 4$ rev. $\min ^{-1}$ for $\geq 5 \mathrm{~s}$. The nature and frequency of verbal encouragement was replicated across trials. Task failure was defined as a drop to $\leq 70 \%$ of self-selected cadence for $>5 \mathrm{~s}$, despite strong verbal encouragement.

\section{Within-Exercise Measures}

Transcranial Doppler sonography was used to measure blood flow velocity in the left middle cerebral artery $\left(\mathrm{MCA}_{\mathrm{v}}\right)$. The same experimenter isonated the motor cortex segment of the MCA 
over the left temporal window using a $2 \mathrm{MHz}$ probe on each visit. Signal quality was optimised and the probe was fixed in position within an adjustable headpiece. Continuous traces of the maximal velocity envelope were recorded and processed offline for determination of beat-bybeat mean velocity. Pulmonary ventilation and gas exchange were measured using a breath-bybreath system (Metalyzer 3B, Cortex Biophysik, Leipzig, Germany). Following orientation to the scales, RPE and breathlessness were obtained using the Borg RPE scale and the modified Borg CR10 Scale, respectively. RPE, breathlessness, $\mathrm{HR}, \mathrm{S}_{\mathrm{p}} \mathrm{O}_{2}$ were recorded at 1-min intervals. Resting $[\mathrm{Hb}]$ in combination with $\mathrm{S}_{\mathrm{p}} \mathrm{O}_{2}$ was used to estimate $\mathrm{C}_{\mathrm{a}} \mathrm{O}_{2}$ at rest and throughout exercise in all conditions using the equation $\mathrm{C}_{\mathrm{a}} \mathrm{O}_{2}=[\mathrm{Hb}] \times 1.39 \times\left(\mathrm{S}_{\mathrm{p}} \mathrm{O}_{2} / 100\right)$. Subsequently, an index of $\mathrm{CD} \mathrm{O}_{2}$ was calculated as the product of $\mathrm{MCA}_{\mathrm{v}}$ and estimated $\mathrm{C}_{\mathrm{a}} \mathrm{O}_{2}$. The estimation of $\mathrm{CDO}_{2}$ in this study is based on the assumption that $\mathrm{MCA}_{\mathrm{v}}$ is a valid surrogate of MCA blood flow. There are uncertainties about the constancy of MCA diameter which prelude this assumption (see (1)), and as such, the data should be interpreted with due caution.

\section{Neuromuscular Assessment}

Neuromuscular data were captured using a data acquisition system and analysed offline using custom-made macroinstructions (PowerLab 26T and LabChart Vv7, ADInstruments Ltd, Oxford, UK). Prior to the neuromuscular assessment, optimal coil position and resting motor threshold were determined (Figure 1B, described below). The neuromuscular assessment (Figure 1C) was completed in $205 \mathrm{~s}$ pre- and post-exercise and was performed within the chamber. The first maximal voluntary contraction $(\mathrm{MVC})$ was performed $\leq 40 \mathrm{~s}$ after task failure. 


\section{Knee-Extensor Force}

Participants sat upright on a custom-built chair with the knees and hips at $90^{\circ}$ of flexion and were secured using straps across trunk and shoulders. Knee-extensor force was measured using a calibrated load cell (Tedea Huntleigh 615, Vishay, Basingstoke, UK) positioned directly behind the point of applied force and connected to a noncompliant cuff attached around the participant's right leg, $1-2 \mathrm{~cm}$ superior to the ankle malleoli. Following a set of preparatory contractions $(2 \mathrm{x}$ $50 \%, 2 \times 75 \%$ and a minimum of $2 \times 100 \%$ 'efforts'), MVCs were performed for $3-5 \mathrm{~s}$ with strong verbal encouragement and visual feedback of force. MVC force was measured as the highest 500-ms plateau.

\section{Electrical Stimulation of the Femoral Nerve}

Single electrical stimuli (200 $\mu$ s pulse width) were delivered to the right femoral nerve via $5 \mathrm{~cm}^{2}$ surface electrodes (CF5050B, Nidd Valley Medical, Hampshire, UK) and a constant-current stimulator (DS7AH, Digitimer Ltd, Hertfordshire, UK). The cathode was positioned over the femoral nerve, high in the femoral triangle. The anode was placed midway between the greater trochanter and the iliac crest. The site of stimulation that produced the highest mechanical twitch force and peak-to-peak M-wave amplitude in the vastus lateralis (VL) was located. Stimulations were delivered at increasing intensity $(10 \mathrm{~mA}+20 \mathrm{~mA})$ until no further increase in either twitch force or M-wave amplitude could be elicited. The plateau intensity was increased by $30 \%$ to ensure supramaximality $(254 \pm 53 \mathrm{~mA})$. Femoral nerve stimulation (FNS) was delivered during and within $2 \mathrm{~s}$ of MVCs to quantify M-waves, potentiated twitch force $\left(\mathrm{Q}_{\mathrm{tw}, \mathrm{pot}}\right)$ and $\mathrm{VA}_{\mathrm{FNS}}$. $\mathrm{VA}_{\mathrm{FNS}}$ was calculated using the interpolated twitch technique (ITT) where the amplitude of the 
superimposed twitch (SIT) was normalized to the corresponding $Q_{t w, p o t}$ using the equation $\mathrm{VA}_{\mathrm{FNS}}$ $(\%)=\left(1-\left(\mathrm{SIT} / \mathrm{Q}_{\mathrm{tw} \cdot \mathrm{pot}}\right)\right) \times 100(7)$.

\section{Transcranial Magnetic Stimulation}

Single TMS pulses (1-ms duration) were delivered with a $110-\mathrm{mm}$ diameter concave doublecone coil powered by a mono-pulse magnetic stimulator (Magstim $200^{2}$, The Magstim Company Ltd, Whitland, UK) with a postero-anterior intracranial current flow. Optimal coil position (location eliciting the largest motor evoked potential (MEP) in the VL and a concurrent small MEP in the biceps femoris (BF) with stimulations delivered at $70 \%$ maximal stimulator output (MSO)) was measured relative to the vertex and clearly marked on the scalp with indelible ink. Resting motor threshold (rMT) was determined at the beginning of each TTF visits using the modified relative frequency method (20), defined as the intensity that elicited a VL MEP of $\geq$ $0.05 \mathrm{mV}$ in three out of six trials (42). Stimulations were delivered at 130\% rMT (18) which corresponded to $70 \pm 11 \% \mathrm{MSO}$ (VL MEP/M $\mathrm{M}_{\text {sup }}$ area of $60-70 \%$ at $50-75 \% \mathrm{MVC}$ ). The BF MEP response was $<20 \%$ of the VL response at all contraction strengths. Participants performed three sets of contractions $(100 \%, 75 \%$ and $50 \%$ MVC, separated by $10 \mathrm{~s}$ rest) with 20 -s rest between sets (Figure 1C). The estimated resting twitch (ERT) was estimated by taking the $y$ intercept of a linear regression (baseline: $r=0.95 \pm 0.04$; fatigued state: $r=0.95 \pm 0.05$ ) of the SIT-voluntary force relationship (43). $\mathrm{VA}_{\mathrm{TMS}}$ was subsequently quantified using the equation $\mathrm{VA}_{\mathrm{TMS}}(\%)=(1-(\mathrm{SIT} / \mathrm{ERT}))^{*} 100$. Where regressions were not adequately linear (defined as $r<$ $0.85(16))$, or an individual set or contraction was problematic, it was excluded and the mean of the two sets was used to estimate ERT. This occurred in $<5 \%$ of evaluations. 


\section{Electromyographic Responses}

Surface electromyography (EMG) was recorded from the right VL and the lateral head of the BF.

The skin was shaved, abraded and cleaned with an alcohol wipe. Two single-use $\mathrm{Ag} / \mathrm{AgCI}$ electrodes (33 x $22 \mathrm{~mm}$, Kendall H59P, Mansfield, MA, USA) were placed in a bipolar configuration (inter-electrode distance of $20 \mathrm{~mm}$ ) over the muscle belly. The reference electrode was placed over the patella. Electrode placement was marked with indelible ink to ensure consistent positioning between visits. Raw EMG signal was amplified (x 1000), digital band-pass filtered $(20 \mathrm{~Hz}-2 \mathrm{kHz})$ and sampled at $4 \mathrm{kHz}$. The peak-to-peak amplitude and area under the curve of the $\mathrm{VL} \mathrm{M}_{\max }$ and $\mathrm{M}_{\text {sup }}$, and $\mathrm{VL}$ and $\mathrm{BF}$ MEP at each contraction strength were quantified. VL MEPs were normalised to the corresponding maximal $M$-wave at rest $\left(\mathrm{M}_{\max }\right)$ or during an MVC $\left(\mathrm{M}_{\text {sup }}\right)$. The cortical silent period (CSP) was measured during three MVCs from stimulus artefact to the continuous resumption of EMG, determined by the same experimenter using visual inspection of the EMG trace.

\section{Statistical Analyses}

Data are presented as mean \pm SD throughout. All statistical procedures were completed using IBM SPSS v22. Prior to ANOVA, homogeneity of variance was confirmed using Levene's test. Data were checked for sphericity using Mauchly's test and if violated, the Greenhouse-Geisser correction was applied. Two-way mixed ANOVA were performed to determine differences in $\mathrm{HR}, \mathrm{S}_{\mathrm{p}} \mathrm{O}_{2}$ and $\mathrm{RPE}$ during the intervention protocol (exposure $\times$ group) and differences in exercise time and HBmass before and after the intervention (trial $\times$ group). For neuromuscular and within-exercise data, three-way mixed design ANOVA were performed (trial $\times$ time $\times$ group), where trial denotes TTF-Pre vs. ISO. For within exercise data, a resting baseline, minute 1 
-4 and the final minute of constant-power cycling were included in the statistical analysis given the duration of the shortest exercise time. Following a significant overall interaction, two-way repeated measures ANOVA were performed in each group (trial $\times$ time). To account for the difference in exercise time after the IH intervention, two-way repeated measures ANOVA were performed in the IH group alone (trial $\times$ time), where trial denotes $\mathrm{TTF}_{\text {-Pre }}$ Vs. TTF-Post. Following a significant interaction effect, post-hoc analysis was conducted using Tukey's HSD tests to localize differences. Statistical significance was set at $p<0.05$. Effect sizes are presented as partial eta squared $\left(\eta_{p}{ }^{2}\right)$ for main and interaction effects and Cohen's $d_{a v}$ for pairwise comparisons.

\section{RESULTS}

\section{Exercise Time (Figure 2)}

Following an interaction of trial $\times$ group, exercise time did not differ significantly before and after the control intervention $(535 \pm 124$ vs. $557 \pm 131 \mathrm{~s}, p>0.05 ; d=0.18)$, but improved by 35 $\pm 18 \%$ after the IH protocol $(535 \pm 213$ to $713 \pm 271 \mathrm{~s}, p<0.05 ; d=0.73)$.

\section{Haematological Measures}

Due to a technical issue, nine participants in the IH group and four participants in the control group completed the post-intervention oCOr measurement $72 \mathrm{~h}$ after the final exposure. No differences were found for any Hbmass, plasma volume, blood volume or [Hb] before and after the intervention (all $p<0.05$ ) (see Table, Supplemental Digital Content 1, Haematological measures before and 72-h after an intervention of intermittent hypoxia (IH) or control protocol in normoxia, http://links.lww.com/MSS/A993). 


\section{Maximal Voluntary Force}

Following an interaction of trial $\times$ time $\times$ group, MVC was reduced from pre- to post-exercise in the control group (time: $p<0.001 ; \eta_{p}{ }^{2}=0.92$ ), with no differences before and after the intervention (trial $\times$ time: $p=0.69 ; \eta_{p}{ }^{2}=0.02$ ). The exercise-induced decrease in MVC in the IH group was alleviated at isotime after the intervention (trial $\times$ time: $p<0.001 ; \eta_{p}{ }^{2}=0.78$, postexercise MVC: $p<0.05 ; d=0.67$ ). When cycling continued to task failure in $\mathrm{TTF}_{\text {-Post, }}$ the resulting decrease in MVC (Figure 3) did not differ before and after the intervention (trial $\times$ time: $\left.p=0.16 ; \eta_{p}^{2}=0.19\right)$

\section{Central Fatigue and Corticospinal Excitability}

Following an interaction of trial $\times$ time $\times$ group, $\mathrm{VA}_{\mathrm{TMS}}$ was reduced post-exercise in the control group (time: $p<0.001 ; \eta_{p}{ }^{2}=0.92$ ), with no differences before and after the intervention (trial $\times$ time: $\left.p=0.52 ; \eta_{p}{ }^{2}=0.06\right)$. As presented in Figure 3 , the exercise-induced decrease in VA (i.e. central fatigue), was alleviated at isotime after the IH intervention (trial $\times$ time: $p=0.012$; $\eta_{p}{ }^{2}=0.49$, post-exercise VA $A_{\mathrm{TMS}}: p<0.05 ; d=1.20$ ). When cycling continued to task failure, the decrease in $\mathrm{VA}_{\mathrm{TMS}}$ did not differ before and after the intervention (trial $\times$ time: $p=0.296 ; \eta_{p}{ }^{2}=$ 0.11). The overall pattern in regards to $\mathrm{VA}_{\mathrm{FNS}}$ was analogous to that described for $\mathrm{VA}_{\mathrm{TMS}}$ (Table 1). No differences were found for corticospinal excitability parameters (all $p>0.05$ ) and data for 100\% MVC are presented in Table 1.

\section{Peripheral Fatigue and Neuromuscular Transmission}

Following an interaction of trial $\times$ time $\times$ group, $\mathrm{Q}_{\mathrm{tw} \text {,pot }}$ was reduced post-exercise in the control group (time: $p<0.001 ; \eta_{p}{ }^{2}=0.93$ ), and the level of peripheral fatigue did not differ after the 
normoxic protocol (trial $\times$ time: $p=0.053 ; \eta_{p}^{2}=0.44$ ). In contrast, the exercise-induced decrease in $\mathrm{Q}_{\mathrm{tw}, \mathrm{pot}}$ was alleviated at isotime after the IH intervention (trial $\times$ time: $p=0.004 ; \eta_{p}{ }^{2}=0.57$, post-exercise $\left.\mathrm{Q}_{\mathrm{tw}, \mathrm{pot}}: p<0.05 ; d=0.94\right)$. However, the level of peripheral fatigue reached at task failure did not differ before and after the IH intervention (trial $\times$ time: $p=0.079 ; \eta_{p}{ }^{2}=0.28$ ). No differences were found for parameters relating to neuromuscular transmission (all $p>0.05$ ) and data are presented in Table 1.

\section{Within-Exercise Measures}

Data for HR, RPE, breathlessness and pulmonary gas exchange are presented in Table 2 .

\section{Pulmonary Ventilation}

Following an interaction of trial $\times$ time $\times$ group, $\dot{V}_{\mathrm{E}}$ was found to be higher at isotime following the IH intervention $(p<0.05 ; d=0.27)$. A higher $\dot{V}_{\mathrm{E}}$ was also observed in $\mathrm{TTF}_{\text {-Pre }} \mathrm{Vs}$. TTF-Post $(p$ $\left.=0.004 ; \eta_{p}{ }^{2}=0.42\right)$, such that $\dot{V}_{\mathrm{E}}$ was $17 \pm 21 \%$ higher at task failure after the intervention $(p<$ $0.05 ; d=0.43)$.

\section{Hemoglobin Oxygen Saturation}

Following an interaction of trial $\times$ time $\times$ group, the profile of decreasing $\mathrm{S}_{\mathrm{p}} \mathrm{O}_{2}$ during exercise in severe hypoxia (Figure 4) did not differ before and after the intervention in the control group (trial $\times$ time: $p=0.45 ; \eta_{p}{ }^{2}=0.12$ ). This is in contrast to the IH group (trial $\times$ time: $p=0.001 ; n p^{2}$ $=0.35)$, where $\mathrm{S}_{\mathrm{p}} \mathrm{O}_{2}$ was higher at isotime after the intervention $(p<0.05 ; d=1.57)$. However, when exercise time was prolonged to task failure, end-exercise $\mathrm{S}_{\mathrm{p}} \mathrm{O}_{2}$ reached the same level as in $\operatorname{TTF}_{-P r e}(p>0.05 ; d<0.1)$. 


\section{Arterial Oxygen Content}

Following an interaction of trial $\times$ time $\times$ group, in the control group, the profile of $\mathrm{C}_{\mathrm{a}} \mathrm{O}_{2}$ did not differ before and after the intervention (trial $\times$ time: $p=0.741 ; \eta_{p}{ }^{2}=0.08$ ). This is in contrast to the $\mathrm{IH}$ group (trial $\times$ time: $p<0.001 ; \eta_{p}{ }^{2}=0.36$ ), where $\mathrm{C}_{\mathrm{a}} \mathrm{O}_{2}$ was higher at isotime: $16.8 \pm 1.1$ vs. $\left.15.9 \pm 0.8 \mathrm{~mL} \mathrm{O}_{2} \cdot \mathrm{dL}^{-1} ; p<0.05 ; d=0.90\right)$. However, at task failure, although the interaction of trial $\times$ time was significant $\left(p=0.041 ; \eta_{p}{ }^{2}=0.20\right)$ no differences were found when post-hoc analysis was conducted.

\section{Cerebral Blood Flow Velocity and Cerebral Oxygen delivery}

Due to an inadequate signal, one participant was removed from the analysis of $\mathrm{MCA}_{\mathrm{v}}$ and the derived estimate of $\mathrm{C}^{\circ} \mathrm{O}_{2}$ ( $\mathrm{IH} n=11$, control $\left.n=7\right)$. No significant differences were found in the profile of $\mathrm{MCA}_{\mathrm{v}}$ or $\mathrm{C}^{\mathrm{D}} \mathrm{O}_{2}$ (i.e. interaction effects) before and after the interventions (all $p>$ 0.05). Data are presented in Figure 4.

\section{The Intervention Protocols}

No incidence of AMS (LLQ score $\geq 3$ ) was observed. Following an interaction of exposure $\times$ group, in the $\mathrm{IH}$ group, resting $\mathrm{S}_{\mathrm{p}} \mathrm{O}_{2}$ improved during exposure 9 and 10 (e.g. $79 \pm 6 \%$ vs. $83 \pm$ $4 \%$ for exposure 1 vs. $10, p<0.05 ; d=0.59$ ). Exercising $\mathrm{S}_{\mathrm{p}} \mathrm{O}_{2}$ in $\mathrm{IH}$ improved from the first to the last exercise bout ( $74 \pm 4 \mathrm{vs}, 78 \pm 4, p<0.05 ; d=1.0$ ). $\mathrm{S}_{\mathrm{p}} \mathrm{O}_{2}$ was $98 \pm 1 \%$ at rest and $97 \pm$ $1 \%$ during exercise in the control group and did not differ over exposures 1 to 10 (all $p>0.05$ ). No differences were found between groups in exercising HR or RPE (all $p>0.05$ ). During the first session of exercise, HR was $131 \pm 15 \mathrm{~b} \cdot \mathrm{min}^{-1}$ and $131 \pm 6 \mathrm{~b} \cdot \mathrm{min}^{-1}$ in $\mathrm{IH}$ and control, respectively. By exposure 10, exercising $\mathrm{HR}$ reduced to $122 \pm 14 \mathrm{~b} \cdot \mathrm{min}^{-1}$ and $124 \pm 5 \mathrm{~b} \cdot \mathrm{min}^{-1}$ in 
IH and control, respectively. In both groups, RPE was $12 \pm 1$ on exposure 1 , and $11 \pm 1$ by exposure 10.

\section{DISCUSSION}

The aim of the present study was to assess both whole-body exercise tolerance and the mechanisms of neuromuscular fatigue in severe hypoxia following an $\mathrm{IH}$ protocol. Exercise tolerance in severe hypoxia improved following an IH protocol completed in the same severity of hypoxia, but not in a control group who completed a matched protocol in normoxia. This is the first study to show that the development of neuromuscular fatigue with whole-body exercise in severe hypoxia is attenuated following an IH protocol. In particular, central fatigue was lower at the same exercise time achieved prior to the IH intervention.

\section{The IH Protocol and Exercise Tolerance in Severe Hypoxia}

The IH protocol involved ten exposures to a low $\mathrm{P}_{\mathrm{I}} \mathrm{O}_{2}(82 \mathrm{mmHg})$ at rest (2-hour duration) with 30 minutes of moderate-intensity exercise $\left(25 \% \dot{W}_{\text {peak }}\right)$ within seven of the sessions. Selecting an optimal hypoxic dose that is both suitable for practical application and capable of eliciting beneficial adaptations is challenging because protocols vary considerably in the literature depending on the aim of the specific study. Nevertheless, in the design of the present study, we

considered the characteristics of $\mathrm{IH}$ protocols (in relation to the combination of exposure and training, the training intensity and duration and the total hypoxic dose) and exercise performance in severe hypoxia as reviewed by Muza et al in 2007 (28) and investigated in later studies (e.g. $(6,7,9,10,24))$. In the initial $\mathrm{IH}$ sessions of the present study, there was an anticipated and pronounced arterial hypoxemia at rest $\left(\mathrm{S}_{\mathrm{p}} \mathrm{O}_{2}<80 \%\right)$, which improved in the last two sessions $(\sim$ 
$83 \%$ ). During the first exercise bout in $\mathrm{IH}, \mathrm{S}_{\mathrm{p}} \mathrm{O}_{2}$ decreased further, to $<75 \%$. This improved significantly by the final exercise bout alone $(\sim 78 \%)$. Comparable improvements in $\mathrm{S}_{\mathrm{p}} \mathrm{O}_{2}$ during hypoxic exercise have been reported during constant-power exercise following an IH protocol (e.g. (7)), although not consistently (6).

Constant-power cycling in $\mathrm{AH}$ resulted in task failure in $8.9 \pm 2.9 \mathrm{~min}$. During the intervention, power output was not equivalent in $\mathrm{IH}$ and control due to the increase in relative exercise intensity at the same absolute power output in severe hypoxia. To detect changes due to the intervention, the exercise intensity in normoxia was adjusted to match heart rate recorded during the first exercise bout in the IH group $\left(\sim 131 \mathrm{~b} \cdot \mathrm{min}^{-1}\right)$. In matching the cardiovascular demand of the exercise, it is noted that exercise was also performed at the same perceived exertion (RPE 12), where $\mathrm{SpO}_{2}$ was significantly greater for the control group (98\%). It was therefore hypoxic exposure and/or hypoxic exercise that elicited an improvement in exercise tolerance in severe hypoxia in the IH group. Although adaptations cannot be attributed to one of these stressors alone, seven sessions of matched-intensity exercise in normoxia did not improve exercise tolerance in severe hypoxia. Indeed, there was no statistical difference from baseline exercise time in the control group, where the mean difference (36 s) was deemed too small to warrant, and justify from an ethical standpoint, a further trial in severe hypoxia. The improvement in exercise time in the IH group was substantial $(\sim 35 \%)$ and systematic (range: $1.1-5.2 \mathrm{~min})$. Given the successful blinding to the intervention and the blinding of all real-time feedback during the cycling trials, we consider it to be highly unlikely that the improvement in exercise tolerance was due to an anticipated benefit of IH (i.e. a placebo effect). 


\section{Neuromuscular Fatigue in Severe Hypoxia}

Constant-power cycling induced neuromuscular fatigue in $\mathrm{AH}$, indicated by a $\sim 20 \%$ decrease in the ability to produce maximal voluntary force in the knee extensors. After the IH protocol, the reduction in MVC force was less pronounced at isotime $(\sim 12 \%)$, but reached pre-intervention levels when exercise continued to task failure. One of the primary limitations to whole-body exercise tolerance in severe hypoxia is exacerbated central fatigue $(4,17)$. The decrease in $\mathrm{VA}_{\mathrm{TMS}}$ from pre- to post-exercise in severe hypoxia prior to the intervention was similar to that reported previously in $\mathrm{AH}(17,19)$. Goodall et al $(19)$ found a $12 \%$ decrease in $\mathrm{VA}_{\mathrm{TMS}}$ following constantpower cycling in $\mathrm{AH}$. After acclimatization, central fatigue was alleviated at isotime and this was attributed, in part, to an improved cerebral $\mathrm{O}_{2}$ availability. However, due to the constraints of the wider project protocol, an improvement in exercise tolerance was not confirmed. In the present study, the IH protocol resulted in an alleviated central fatigue at isotime, where the decrease from baseline was no longer significant. When exercise was permitted to continue to task failure after the IH intervention, central fatigue (and indeed the overall decrease in MVC force) ultimately reached the same levels that coincided with task failure before the intervention $(12 \%$ decrease in $\left.\mathrm{VA}_{\mathrm{TMS}}\right)$. We therefore propose that the alleviation of the central contribution to neuromuscular fatigue is an important, though not necessarily the singular, mechanism by which exercise was prolonged following the $\mathrm{IH}$ protocol.

The mechanisms for the alleviation of central fatigue may be related to improved cerebral oxygenation secondary to an improved $\mathrm{CD}_{2}$ (11). A number of researchers have substantiated a link between a reduced $\mathrm{C} \dot{D} \mathrm{O}_{2}$ and the impairment to whole-body exercise that occurs in severe hypoxia (e.g. (48)). However, a challenge in the research area is isolating the influence of a 
systemic improvement in oxygenation (i.e. $\mathrm{SpO}_{2}$ ) from an improvement in cerebral oxygenation. Isolating the effect of systemic and cerebral oxygenation requires innovative experimental procedures such as $\mathrm{CO}_{2}$ clamping, which increases $\mathrm{CBF}$ and therefore $\mathrm{CD}_{2}$. Interestingly, increasing $\mathrm{C}^{\circ} \mathrm{O}_{2}$ in $\mathrm{AH}$ has not been shown to improve exercise tolerance (12). However, the method is problematic during whole-body exercise (e.g. due to increased respiratory muscle work), and has only been performed with a neuromuscular assessment in a single-limb model (36). In the present study, although the estimate of $\mathrm{C}_{\mathrm{a}} \mathrm{O}_{2}$ was higher at isotime after the IH intervention (due to the improvement in $\mathrm{S}_{\mathrm{p}} \mathrm{O}_{2}$ and not $[\mathrm{Hb}]$ ), $\mathrm{CBF}$ and $\mathrm{C}^{\circ} \mathrm{O}_{2}$ were not, despite the improvement in exercise time. The relationship between $\mathrm{C}^{\circ} \mathrm{O}_{2}$, exercise tolerance and central fatigue in severe hypoxia remains unresolved (39). However, the eventual use of $\mathrm{O}_{2}$ in mitochondrial oxidation depends not only on $\mathrm{CDO}_{2}$ but on the capillary $\mathrm{O}_{2}$ tension, the $\mathrm{O}_{2}$ conductance from capillary to mitochondria and the cerebral metabolic rate of $\mathrm{O}_{2}$ (31). Under normoxic conditions there is a tight coupling of the cerebral metabolic rate of $\mathrm{O}_{2}$ and $\mathrm{CBF}(30)$. During physiological increases in neuronal activity (e.g., synaptic transmission and firing rate), there is an uncoupling of these variables such that $\mathrm{CBF}$ largely exceeds the consumption of $\mathrm{O}_{2}$ in tissue (13). It may be that the signal for reduced central motor output depends on a step that is uncoupled with $\mathrm{C} \dot{D} \mathrm{O}_{2}$ during whole-body exercise in severe hypoxia, and this may be altered with an IH protocol. However, this is speculative and further studies on the relationship between cerebral $\mathrm{O}_{2}$ metabolism and central fatigue in severe hypoxia are warranted.

Neither the CSP, as a representation GABA(B) receptor-mediated inhibition of cortical excitability (40), or the MEP, used to assess changes in the state of excitability in the corticospinal system (8), were modulated pre- to post-exercise exercise in severe hypoxia, or by 
the intervention itself. Previous findings indicate time-dependent increases in corticospinal excitability (at rest) with severe hypoxia $(3,35)$. However, both studies used continuous exposures ( $3 \mathrm{~h}$ and 14 days, respectively) and it may be that the discontinuous nature of an IH protocol (i.e. the wash-out in normoxia) masked any transient neurophysiological alterations over the time-course of an $\mathrm{IH}$ protocol. This warrants further investigation, given the therapeutic potential of IH $(29,46)$.

As evidenced by an increase in $\dot{V}_{\mathrm{E}}$ and decrease in $\mathrm{P}_{\mathrm{ET}} \mathrm{CO}_{2}$ following the IH intervention, the $\mathrm{IH}$ protocol used conferred a level of ventilatory adaptation to hypoxic exercise. This resulted in an increase in $\mathrm{S}_{\mathrm{p}} \mathrm{O}_{2}$ during constant-power cycling following the $\mathrm{IH}$ protocol. A proposed threshold of arterial hypoxemia where hypoxia-sensitive mechanisms originating in the CNS are thought to override other inhibitory influences on central motor output (i.e. afferent feedback from the exercising limb) during whole-body exercise, is below $70-75 \%(4,11)$. We note that at isotime following the $\mathrm{IH}$ intervention, $\mathrm{S}_{\mathrm{p}} \mathrm{O}_{2}$ was $79 \%$ (vs. $70 \%$ at task failure in $\mathrm{TTF}_{\text {-Pre }}$ ). A number of previous studies have shown similar ventilatory adaptations with $\mathrm{IH}$ which resulted in an increased $\dot{V}_{\mathrm{E}}$ and $\mathrm{S}_{\mathrm{p}} \mathrm{O}_{2}$ during hypoxic exercise, augmented by increased hypoxic chemosensitivity $(7,10,28)$. Limited studies have investigated exercise tolerance in severe hypoxia, but some have shown improvements in cycle time-trial performance comparable to $\mathrm{CH}(5,7)$. More recently, a study that used four exposures of $4 \mathrm{~h}$ to $\mathrm{P}_{\mathrm{I}} \mathrm{O}_{2} \approx 92 \mathrm{mmHg}$, increased exercise $\dot{V}_{\mathrm{E}}$ and $\mathrm{S}_{\mathrm{p}} \mathrm{O}_{2}$ were observed without changes in cerebral oxygenation or constant-power cycling to task failure in hypoxia (10). A beneficial effect of IH on exercise tolerance in severe hypoxia is not a consistent finding $(6,9)$, and the disparity may be due to differences relating to protocol and hypoxic dose. 
In the present study, we found no change in Hbmass, plasma volume or [Hb]. Hbmass is a measure of $\mathrm{O}_{2}$ carrying capacity that is not subject to vascular volume shifts. A recent study reported an increase in Hbmass following an IH protocol in moderate hypoxia (34). This is surprising given the evidence suggesting that the total duration of hypoxic exposure required to produce a change in Hbmass is equivalent to more than $\sim \mathrm{d}$ continuous exposure (32).

\section{The Peripheral Contribution to Neuromuscular Fatigue}

In $\mathrm{AH}$, peripheral locomotor muscle fatigue was identified as a decrease in potentiated quadriceps twitch force by $\sim 20 \%$. The results of earlier studies indicate that in the severeintensity domain, the level of peripheral fatigue at task failure in $\mathrm{AH}$ is less than that reached at task failure in normoxia $(>30 \%)$ (e.g. (4)). In severe hypoxia, task disengagement occurs before metabolic disturbance reaches levels attained at the end of the same task performed in normoxia. For this reason, we do not consider peripheral fatigue to be a major limitation to whole-body exercise under these specific and extreme conditions. Nevertheless, following the IH protocol, the decrease in $\mathrm{Q}_{\text {tw.pot }}$ was less prominent at isotime $(\sim 16 \%)$. This is in contrast to the findings following a 14-day exposure to high altitude, where the development of peripheral fatigue was not alleviated (3). The mechanisms for this are equivocal but may be related to a lower limb blood flow and therefore limb $\mathrm{O}_{2}$ delivery, an important regulator of peripheral fatigue (2). Speculatively, in the present study, an unchanged limb blood flow coupled with an increase in $\mathrm{C}_{\mathrm{a}} \mathrm{O}_{2}$ is one explanation for the reduction in peripheral fatigue. Alternatively, an exercise $x$ hypoxia interaction may have induced skeletal muscle adaptations (21) that delayed the development of peripheral fatigue such that it was lower at isotime, but ultimately reached the same levels at task failure. 
The decision to disengage from a task can be described as an internally coordinated response to internal and/or external stimuli, i.e. a behaviour (23). It would be simplistic to ascribe this solely to lower-level neurophysiological properties (22). The perception of the sensations associated with hypoxic exercise is an important consideration, and both perceived limb discomfort and breathlessness (notably, in spite of a higher $\dot{V}_{\mathrm{E}}$ ), were also lower at isotime. We further acknowledge that task failure in severe hypoxia is likely to have a cognitive component (44). Disentangling the relative contributions of these complex and interactive processes is a major challenge for exercise scientists and in hypoxic physiology, warrants further consideration.

In summary, the novel findings of this study were that whole-body exercise tolerance in severe hypoxia was prolonged following a protocol of intermittent hypoxia involving exposure and exercise, but not in a control group who performed a matched protocol in normoxia. At isotime following the IH intervention, the central contribution to neuromuscular fatigue was alleviated. These alterations occurred alongside an augmented ventilatory response to hypoxic exercise which improved the pronounced arterial hypoxemia induced by hypoxic exercise in the severeintensity domain. 


\section{ACKNOWLEDGMENTS}

The authors wish to acknowledge Dr Jamie Pringle and the English Institute of Sport for loan of equipment and technical support related to the oCOr.

\section{CONFLICTS OF INTEREST AND SOURCE OF FUNDING}

No conflicts of interest, financial or otherwise, are declared by the authors. The authors declare that the results of the study are presented clearly, honestly, and without fabrication, falsification, or inappropriate data manipulation. The results of the present study do not constitute endorsement by the American College of Sports Medicine. 


\section{REFERENCES}

1. Ainslie PN, Subudhi AW. Cerebral blood flow at high altitude. High Atitude Medicine \& Biology. 2014;15(2):133-140.

2. Amann M, Calbet JAL. Convective oxygen transport and fatigue. Journal of Applied Physiology. 2008;104(3):861-870.

3. Amann M, Goodall S, Twomey R, Subudhi AW, Lovering AT, Roach RC. AltitudeOmics: On the consequences of high-altitude acclimatization for the development of fatigue during locomotor exercise in humans. Journal of Applied Physiology. 2013;115(5):634-642.

4. Amann M, Romer LM, Subudhi AW, Pegelow DF, Dempsey JA. Severity of arterial hypoxaemia affects the relative contributions of peripheral muscle fatigue to exercise performance in healthy humans. The Journal of Physiology. 2007;581(1):389-403.

5. Beidleman BA, Muza SR, Fulco CS, et al. Intermittent altitude exposures improve muscular performance at 4,300 m. Journal of Applied Physiology. 2003;95(5):1824-1832.

6. Beidleman BA, Muza SR, Fulco CS, et al. Intermittent hypoxic exposure does not improve endurance performance at altitude. Medicine and Science in Sports and Exercise. 2009;41(6):1317-1325.

7. Beidleman BA, Muza SR, Fulco CS, et al. Seven intermittent exposures to altitude improves exercise performance at $4300 \mathrm{~m}$. Medicine and Science in Sports and Exercise. 2008;40(1):141-148.

8. Bestmann S, Krakauer JW. The uses and interpretations of the motor-evoked potential for understanding behaviour. Experimental Brain Research. 2015;233(3):679-689. 
9. Debevec T, Amon M, Keramidas ME, Kounalakis SN, Pisot R, Mekjavic IB. Normoxic and hypoxic performance following 4 weeks of normobaric hypoxic training. Aviation, Space, and Environmental Medicine. 2010;81(4):387-393.

10. Debevec T, Mekjavic IB. Short intermittent hypoxic exposures augment ventilation but do not alter regional cerebral and muscle oxygenation during hypoxic exercise. Respiratory Physiology \& Neurobiology. 2012;181(2):132-142.

11. Fan J-L, Kayser B. Fatigue and Exhaustion in Hypoxia: The Role of Cerebral Oxygenation. High Altitude Medicine \& Biology. 2016;17(2):72-84.

12. Fan J-L, Kayser B. The effect of adding $\mathrm{CO} 2$ to hypoxic inspired gas on cerebral blood flow velocity and breathing during incremental exercise. PloS one. 2013;8(11):e81130.

13. Fox PT, Raichle ME, Mintun MA, Dence C. Nonoxidative glucose consumption during focal physiologic neural activity. Science. 1988;241(4864):462-464.

14. Fulco, CS, Rock, et al. Maximal and submaximal exercise performance at altitude. Aviation, Space, and Environmental Medicine. 1998;69(8):793-801.

15. Gallagher SA, Hackett PH. High-altitude illness. Emergency Medicine Clinics of North America. 2004;22(2):329-355.

16. Girard O, Bishop DJ, Racinais S. Neuromuscular adjustments of the quadriceps muscle after repeated cycling sprints. PloS one. 2013;8(5):e61793.

17. Goodall S, González-Alonso J, Ali L, Ross E, Romer L. Supraspinal fatigue after normoxic and hypoxic exercise in humans. The Journal of Physiology. 2012;590(11):2767-2782.

18. Goodall S, Romer LM, Ross EZ. Voluntary activation of human knee extensors measured using transcranial magnetic stimulation. Experimental Physiology. 2009;94(9):995-1004. 
19. Goodall S, Twomey R, Amann M, et al. AltitudeOmics: Exercise-induced supraspinal fatigue is attenuated in healthy humans after acclimatization to high altitude. Acta Physiologica. 2014;210(4):875-888.

20. Groppa S, Oliviero A, Eisen A, et al. A practical guide to diagnostic transcranial magnetic stimulation: report of an IFCN committee. Clinical Neurophysiology. 2012;123(5):858882.

21. Hoppeler H, Klossner S, Vogt M. Training in hypoxia and its effects on skeletal muscle tissue. Scandinavian Journal of Medicine \& Science in Sports. 2008;18 Suppl 1(s1):38-49.

22. Krakauer JW, Ghazanfar AA, Gomez-Marin A, MacIver MA, Poeppel D. Neuroscience needs behavior: Correcting a reductionist bias. Neuron. 2017;93(3):480-490.

23. Levitis DA, Lidicker WZ, Freund G. Behavioural biologists do not agree on what constitutes behaviour. Animal Behaviour. 2009;78(1):103-110.

24. Mekjavic IB, Debevec T, Amon M, Keramidas ME, Kounalakis SN. Intermittent Normobaric Hypoxic Exposures at Rest: Effects on Performance in Normoxia and Hypoxia. Aviation, Space, and Environmental Medicine. 2012;83(10):942-950.

25. Merton PA. Voluntary strength and fatigue. The Journal of Physiology. 1954;123(3):553564.

26. Millet GP, Roels B, Schmitt L, Woorons X, Richalet J-P. Combining Hypoxic Methods for Peak Performance. Sports Medicine. 2010;40(1):1-25.

27. Mishra KP, Ganju L. Influence of high altitude exposure on the immune system: a review. Immunological Investigations. 2010;39(3):219-234.

28. Muza SR. Military applications of hypoxic training for high-altitude operations. Medicine and Science in Sports and Exercise. 2007;39(9):1625-1631. 
29. Navarrete-Opazo A, Mitchell GS. Therapeutic potential of intermittent hypoxia: a matter of dose. American Journal of Physiology Regulatory, Integrative and Comparative Physiology. 2014;307(10):1181-1197.

30. Raichle ME, Grubb RL, Gado MH, et al. Correlation Between Regional Cerebral Blood Flow and Oxidative Metabolism. Archives of Neurology. 1976;33(8):523.

31. Rasmussen P, Dawson EA, Nybo L, van Lieshout JJ, Secher NH, Gjedde A. Capillaryoxygenation-level-dependent near-infrared spectrometry in frontal lobe of humans. Journal of Cerebral Blood Flow \& Metabolism. 2006;27(5):1082-1093.

32. Rasmussen P, Siebenmann C, Díaz V, Lundby C. Red cell volume expansion at altitude: a meta-analysis and Monte Carlo simulation. Medicine and Science in Sports and Exercise. 2013;45(9):1767-1772.

33. Roach RC, Bartsch P, Hackett PH. Hypoxia and Molecular Medicine: The Lake Louise Acute Mountain Sickness Scoring System.; 1993.

34. Robach P, Bonne T, Flück D, et al. Hypoxic training: effect on mitochondrial function and aerobic performance in hypoxia. Medicine and Science in Sports and Exercise. 2014;46(10):1936-1945.

35. Rupp T, Jubeau M, Wuyam B, et al. Time-dependent effect of acute hypoxia on corticospinal excitability in healthy humans. Journal of Neurophysiology. 2012;108(5):1270-1277.

36. Rupp T, Mallouf TLR, Perrey S, Wuyam B, Millet GY, Verges S. CO2 Clamping, Peripheral and Central Fatigue during Hypoxic Knee Extensions in Men. Medicine and Science in Sports and Exercise. 2015;47(12):2513-2524. 
37. Ryan BJ, Wachsmuth NB, Schmidt WF, et al. AltitudeOmics: rapid hemoglobin mass alterations with early acclimatization to and de-acclimatization from $5260 \mathrm{~m}$ in healthy humans. PloS one. 2014;9(10):e108788.

38. Schmidt W, Prommer N. The optimised CO-rebreathing method: a new tool to determine total haemoglobin mass routinely. European Journal of Applied Physiology. 2005;95(56):486-495.

39. Siebenmann C, Rasmussen P. Does cerebral hypoxia facilitate central fatigue? Experimental Physiology. February 2016.

40. Stetkarova I, Kofler M. Differential effect of baclofen on cortical and spinal inhibitory circuits. Clinical Neurophysiology: Official Journal of the International Federation of Clinical Neurophysiology. 2013;124(2):339-345.

41. Subudhi AW, Bourdillon N, Bucher J, et al. AltitudeOmics: the integrative physiology of human acclimatization to hypobaric hypoxia and its retention upon reascent. PloS one. 2014;9(3):e92191.

42. Temesi J, Gruet M, Rupp T, Verges S, Millet GY. Resting and active motor thresholds versus stimulus-response curves to determine transcranial magnetic stimulation intensity in quadriceps femoris. Journal of Neuroengineering and Rehabilitation. 2014;11(1):40.

43. Todd G, Taylor JL, Gandevia SC. Measurement of voluntary activation of fresh and fatigued human muscles using transcranial magnetic stimulation. The Journal of Physiology. 2003;551(2):661-671.

44. Torres-Peralta R, Losa-Reyna J, Morales-Alamo D, et al. Increased PIO2 at exhaustion in hypoxia enhances muscle activation and swiftly relieves fatigue: a placebo or a PIO2 dependent effect? Frontiers in Physiology. 2016;7(333). 
45. Turner G, Pringle JSM, Ingham SA, Fudge BW, Richardson AJ, Maxwell NS. The influence of carbon monoxide bolus on the measurement of total haemoglobin mass using the optimized CO-rebreathing method. Physiological measurement. 2014;35(2):N11-9.

46. Verges S, Chacaroun S, Godin-Ribuot D, Baillieul S. Hypoxic conditioning as a new therapeutic modality. Frontiers in Pediatrics. 2015;3:58.

47. Verges S, Rupp T, Jubeau M, et al. Cerebral perturbations during exercise in hypoxia. American Journal of Physiology Regulatory, Integrative and Comparative Physiology. 2012;302(8):903-916.

48. Vogiatzis I, Louvaris Z, Habazettl H, et al. Frontal cerebral cortex blood flow, oxygen delivery and oxygenation during normoxic and hypoxic exercise in athletes. The Journal of Physiology. 2011;589(Pt 16):4027-4039. 


\section{FIGURE CAPTIONS}

Figure 1. Overview of the experimental protocol (A), the constant-power cycling trial visits (B) and the neuromuscular assessment (C). Fam ${ }^{1}$ and $\mathrm{Fam}^{2}$, familiarisation sessions one and two; Max, measurement of maximal $\mathrm{O}_{2}$ uptake and peak power; oCOr, optimised carbon monoxide rebreathing method; TTF, trial to task failure; ISO, constant-power cycling to isotime; rMT, resting motor threshold; FNS, femoral nerve stimulation; TMS, transcranial magnetic stimulation. *Denotes exposures on which 30 min exercise was performed. †Indicates that this trial did not differ from TTF-Pre and was treated as an isotime trial.

Figure 2. Time to task failure (s) with constant-power cycling in severe hypoxia before (Pre) and after (Post) a protocol of intermittent hypoxia (IH) or a matched protocol in normoxia (Control). ${ }^{*} p<0.05$, Pre vs. Post. The mean is plotted as the closed circle.

Figure 3. Neuromuscular measures made Pre- (open bars) and Post- (closed bars) constantpower cycling in severe hypoxia, before and after a protocol of intermittent hypoxia ( $\mathrm{IH}$, left column) or a matched protocol in normoxia (Control, right column). MVC, maximal voluntary contraction; $\mathrm{VA}_{\mathrm{TMS}}$, cortical voluntary activation; $\mathrm{Q}_{\mathrm{tw}, \mathrm{pot}}$, potentiated quadriceps twitch force; TTF, time to task failure. ${ }^{*} p<0.05$ vs. Post. $\dagger p<0.05$, Post-exercise in $\mathrm{TTF}_{\text {-Pre. }}$ 
Figure 4. Hemoglobin oxygen saturation $\left(\mathrm{S}_{\mathrm{p}} \mathrm{O}_{2}\right.$, top row), cerebral blood flow velocity ( $\mathrm{MCA}_{\mathrm{v}}$, middle row $)$ and cerebral oxygen delivery index $\left(\mathrm{C}^{\circ} \mathrm{O}_{2}\right.$, bottom row $)$ in the intermittent hypoxia group (IH, left column) and control group (right column) during TTF-Pre (open circles) and isotime (grey circles). ${ }^{*} p<0.05$ vs. ISO.

Copyright (C) 2017 by the American College of Sports Medicine. Unauthorized reproduction of this article is prohibited. 


\section{Figure 1}

A

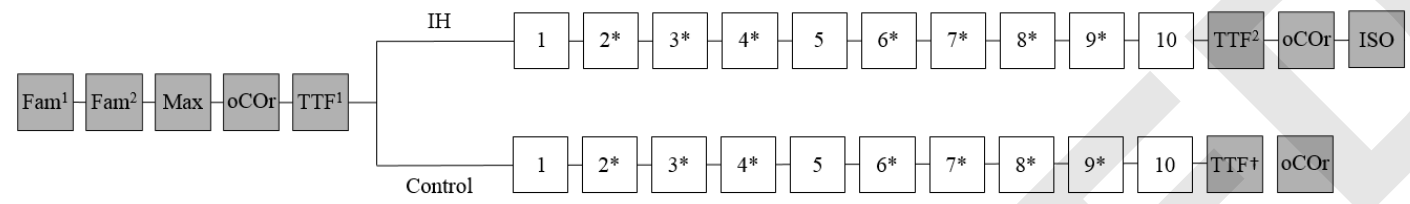

B

C

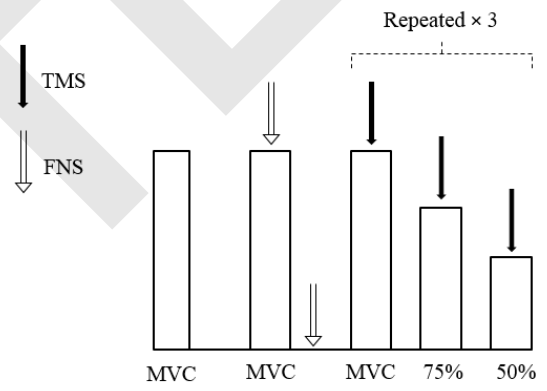


Figure 2
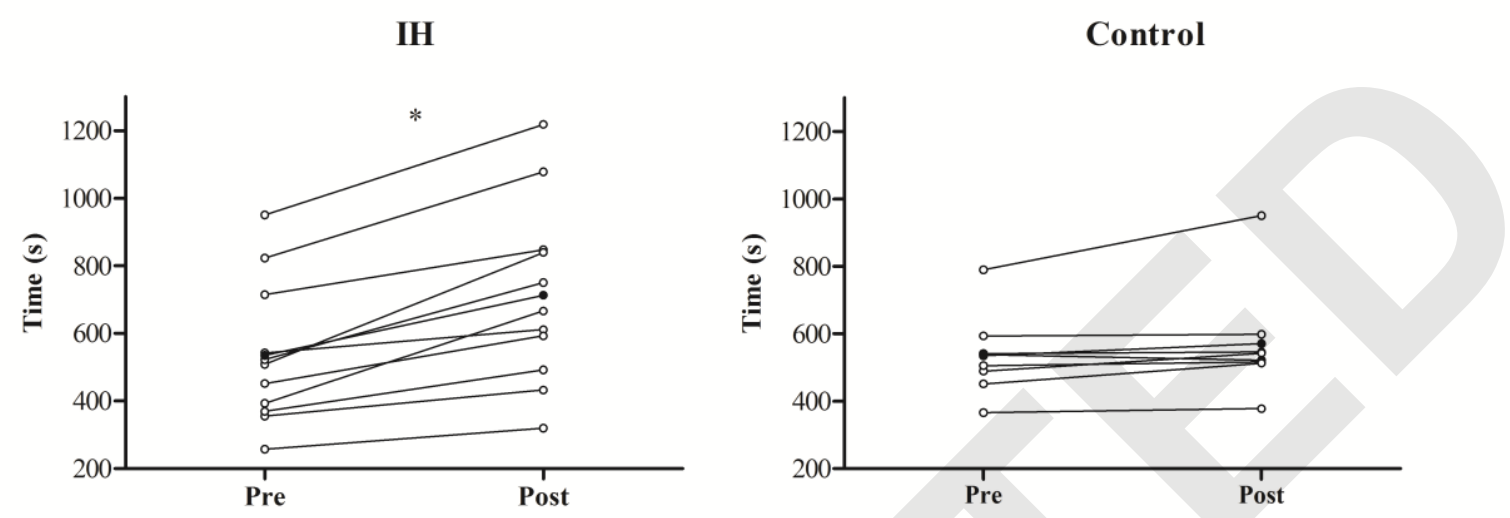
Figure 3
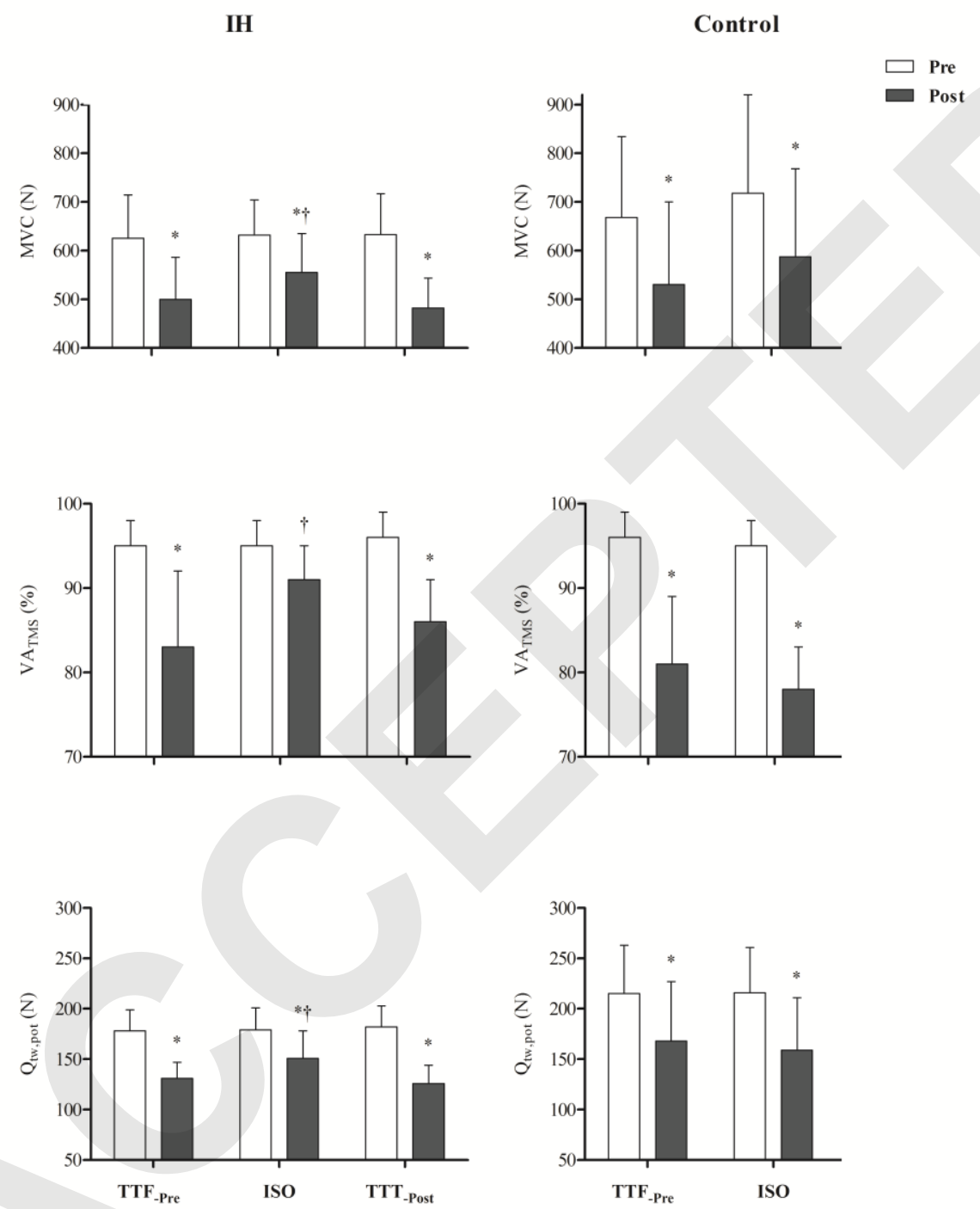


\section{Figure 4}
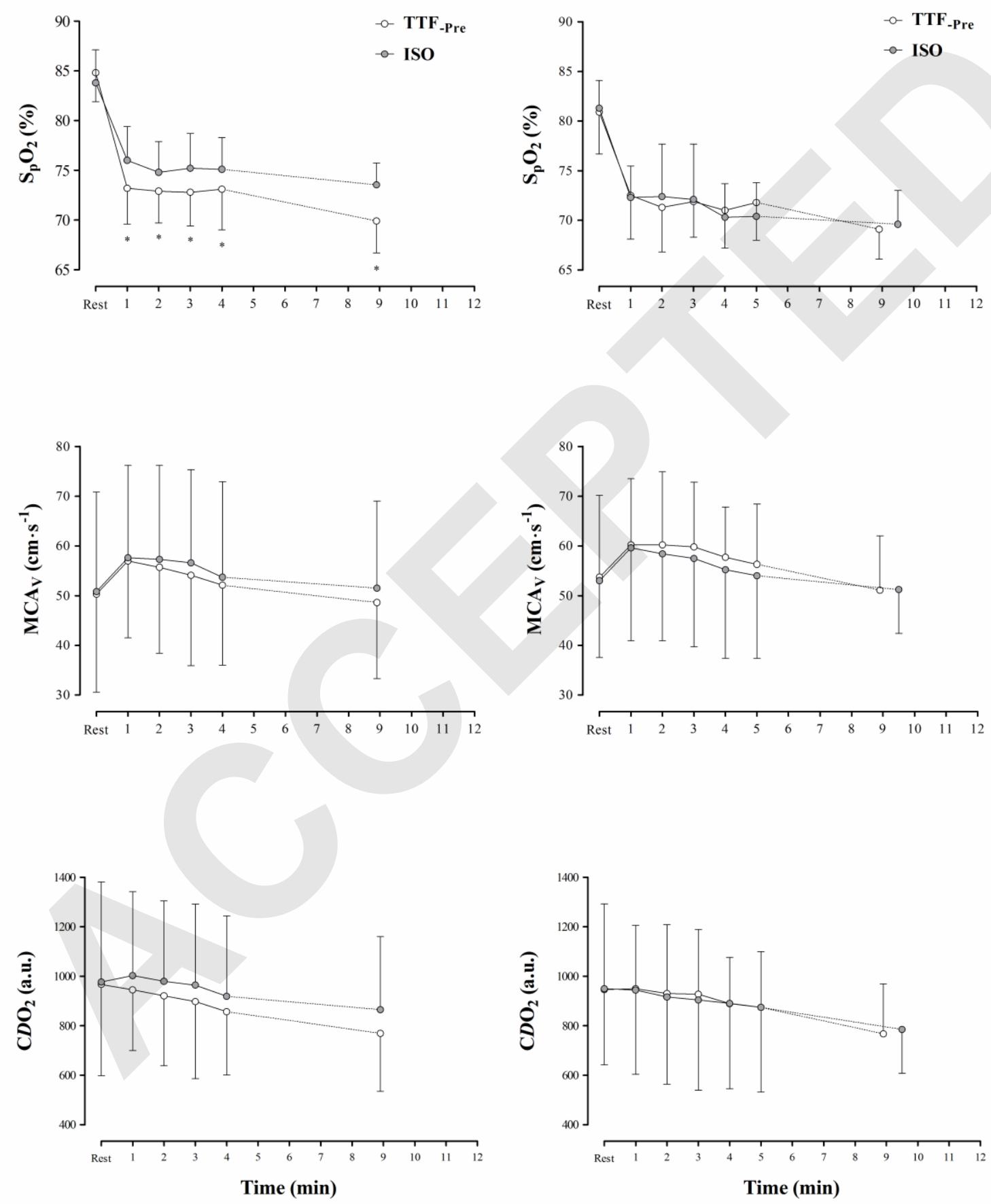
Table 1. Neuromuscular parameters pre and post constant-power cycling to task failure, before and after a protocol of intermittent hypoxia (IH) or a matched control protocol in normoxia.

\begin{tabular}{|c|c|c|c|c|c|c|c|}
\hline & & \multicolumn{2}{|c|}{ TTF $_{\text {-Pre }}$} & \multicolumn{2}{|c|}{ ISO } & \multicolumn{2}{|c|}{ TTF.Post $_{\text {.P }}$} \\
\hline & & Pre & Post & Pre & Post & Pre & Post \\
\hline \multirow[b]{2}{*}{$\mathbf{M}_{\max }$ amplitude (mV) } & $\mathrm{IH}$ & $6.2 \pm 1.9$ & $5.6 \pm 1.6$ & $6.5 \pm 3.2$ & $6.1 \pm 3.5$ & $5.7 \pm 2.2$ & $5.8 \pm 1.9$ \\
\hline & $\mathrm{CON}$ & $6.0 \pm 2.6$ & $4.9 \pm 2.4$ & $5.9 \pm 2.4$ & $5.3 \pm 2.0$ & & \\
\hline \multirow{2}{*}{$\mathbf{M}_{\max } \operatorname{area}\left(\mathrm{mV} \cdot \mathrm{ms}^{-1}\right)$} & $\mathrm{IH}$ & $40.5 \pm 11.6$ & $40.8 \pm 11.9$ & $44.2 \pm 10.1$ & $39.3 \pm 17.4$ & $37.4 \pm 16.0$ & $42.1 \pm 16.2$ \\
\hline & $\mathrm{CON}$ & $40.4 \pm 16.4$ & $34.4 \pm 19.1$ & $40.5 \pm 15.3$ & $40.1 \pm 16.9$ & & \\
\hline \multirow[b]{2}{*}{$\mathrm{VAANS}_{\mathrm{FN}}(\%)$} & $\mathrm{IH}$ & $92 \pm 3$ & $85 \pm 4^{*}$ & $93 \pm 5$ & $90 \pm 4 \dagger$ & $93 \pm 3$ & $86 \pm 3^{*}$ \\
\hline & $\mathrm{CON}$ & $93 \pm 3$ & $86 \pm 3^{*}$ & $92 \pm 3$ & $85 \pm 5^{*}$ & & \\
\hline \multirow{2}{*}{$\mathbf{M}_{\text {sup }}$ amplitude (mV) } & $\mathrm{IH}$ & $6.2 \pm 2.1$ & $5.8 \pm 1.6$ & $7.3 \pm 3.3$ & $6.6 \pm 3.6$ & $6.3 \pm 2.1$ & $5.8 \pm 1.9$ \\
\hline & $\mathrm{CON}$ & $7.4 \pm 2.1$ & $6.0 \pm 3.0$ & $7.1 \pm 2.7$ & $5.5 \pm 2.4$ & & \\
\hline \multirow{2}{*}{$\mathbf{M}_{\text {sup }} \operatorname{area}\left(\mathrm{mV} \cdot \mathrm{ms}^{-1}\right)$} & $\mathrm{IH}$ & $41.1 \pm 11.5$ & $36.7 \pm 8.1$ & $45.4 \pm 16.0$ & $41.5 \pm 18.1$ & $43.0 \pm 12.4$ & $36.5 \pm 12.9$ \\
\hline & $\mathrm{CON}$ & $38.3 \pm 11.0$ & $39.7 \pm 21.4$ & $37.4 \pm 11.5$ & $32.6 \pm 15.7$ & & \\
\hline \multirow[b]{2}{*}{ MEP/M $\mathbf{M}_{\text {sup }}$ amplitude } & $\mathrm{IH}$ & $0.53 \pm 0.12$ & $0.50 \pm 0.13$ & $0.46 \pm 0.13$ & $0.48 \pm 0.15$ & $0.50 \pm 0.18$ & $0.54 \pm 0.14$ \\
\hline & $\mathrm{CON}$ & $0.40 \pm 0.10$ & $0.46 \pm 0.12$ & $0.50 \pm 0.14$ & $0.52 \pm 0.07$ & & \\
\hline \multirow[b]{2}{*}{ MEP/M $\mathbf{M}_{\text {sup }}$ area } & $\mathrm{IH}$ & $0.63 \pm 0.15$ & $0.66 \pm 0.15$ & $0.56 \pm 0.10$ & $0.61 \pm 0.17$ & $0.59 \pm 0.13$ & $0.71 \pm 0.11$ \\
\hline & $\mathrm{CON}$ & $0.59 \pm 0.10$ & $0.58 \pm 0.12$ & $0.67 \pm 0.13$ & $0.73 \pm 0.16$ & & \\
\hline \multirow{2}{*}{$\operatorname{CSP}(\mathrm{ms})$} & $\mathrm{IH}$ & $169 \pm 46$ & $156 \pm 45$ & $179 \pm 43$ & $169 \pm 50$ & $183 \pm 47$ & $172 \pm 48$ \\
\hline & $\mathrm{CON}$ & $179 \pm 85$ & $176 \pm 77$ & $174 \pm 74$ & $164 \pm 70$ & & \\
\hline \multirow{2}{*}{ ERT/MVC (\%) } & $\mathrm{IH}$ & $21 \pm 10$ & $14 \pm 5$ & $20 \pm 8$ & $13 \pm 4$ & $20 \pm 8$ & $14 \pm 6$ \\
\hline & $\mathrm{CON}$ & $25 \pm 8$ & $15 \pm 7$ & $21 \pm 10$ & $13 \pm 8$ & & \\
\hline
\end{tabular}

MVC, maximal voluntary contraction; $\mathrm{M}_{\max }$, maximal muscle compound action potential; $\mathrm{M}_{\text {sup }}$, superimposed maximal muscle compound action potential; MEP, motor evoked potential, CSP, cortical silent period; ERT, estimated resting twitch. ${ }^{*} p<0.05$ vs. pre-exercise. $\dagger p<0.05$ vs. postexercise in $\mathrm{TTF}_{-\mathrm{Pre}}$. 
Table 2. Within-exercise data at rest (following a $15 \mathrm{~min}$ wash-in period to severe hypoxia) and in the final minute of exercise during TTFs before and after an intermittent hypoxia protocol or a matched control protocol in normoxia.

\begin{tabular}{|c|c|c|c|c|c|c|c|}
\hline & & & TTF $_{\text {-Pre }}$ & ISO & A & TTF.Post $_{\text {-Pon }}$ & B \\
\hline \multirow{4}{*}{$\begin{array}{c}\dot{V}_{\mathrm{E}} \\
\left(\mathbf{L} \cdot \mathbf{m i n}^{-1}\right)\end{array}$} & \multirow{2}{*}{$\mathrm{IH}$} & Rest & $16.7 \pm 5.8$ & $17.7 \pm 6.0$ & $t^{*}$ & $18.3 \pm 6.5$ & $\hat{t}^{\#}$ \\
\hline & & End-Ex & $145.1 \pm 17.9$ & $150.1 \pm 18.5$ & * & $158.8 \pm 21.9$ & $*$ \\
\hline & \multirow{2}{*}{$\mathrm{CON}$} & Rest & $17.1 \pm 4.8$ & $18.9 \pm 5.0$ & & & \\
\hline & & End-Ex & $151.2 \pm 16.3$ & $150.9 \pm 16.8$ & & & \\
\hline \multirow{4}{*}{$\begin{array}{l}\mathrm{P}_{\mathrm{ET}} \mathrm{CO}_{2} \\
(\mathrm{mmHg})\end{array}$} & \multirow{2}{*}{$\mathrm{IH}$} & Rest & $38.1 \pm 4.8$ & $33.8 \pm 2.2$ & $\dagger^{*} *$ & $34.4 \pm 3.2$ & $\dagger^{\#}$ \\
\hline & & End-Ex & $28.1 \pm 4.2$ & $27.1 \pm 3.9$ & & $24.7 \pm 2.6$ & \\
\hline & \multirow{2}{*}{$\mathrm{CON}$} & Rest & $33.7 \pm 2.8$ & $33.9 \pm 3.4$ & & & \\
\hline & & End-Ex & $25.1 \pm 2.4$ & $25.1 \pm 2.0$ & & & \\
\hline \multirow{4}{*}{$\begin{array}{c}\dot{V} \mathbf{O}_{2} \\
\left(\mathrm{~L} \cdot \min ^{-1}\right)\end{array}$} & \multirow{2}{*}{$\mathrm{IH}$} & Rest & $0.52 \pm 0.14$ & $0.49 \pm 0.15$ & $\dagger$ & $0.50 \pm 0.15$ & $\dagger$ \\
\hline & & End-Ex & $2.42 \pm 0.48$ & $2.29 \pm 0.32$ & & $2.41 \pm 0.28$ & \\
\hline & \multirow{2}{*}{$\mathrm{CON}$} & Rest & $0.52 \pm 0.17$ & $0.57 \pm 0.12$ & & & \\
\hline & & End-Ex & $2.49 \pm 0.29$ & $2.47 \pm 0.46$ & & & \\
\hline \multirow{4}{*}{$\begin{array}{c}\dot{\mathrm{V}} \mathrm{CO}_{2} \\
\left(\mathrm{~L} \cdot \mathbf{m i n}^{-1}\right)\end{array}$} & \multirow{2}{*}{$\mathrm{IH}$} & Rest & $0.62 \pm 0.16$ & $0.60 \pm 0.18$ & $\dagger$ & $0.61 \pm 0.20$ & $\dagger$ \\
\hline & & End-Ex & $3.60 \pm 0.37$ & $3.38 \pm 0.33$ & & $3.34 \pm 0.35$ & \\
\hline & \multirow{2}{*}{$\mathrm{CON}$} & Rest & $0.61 \pm 0.09$ & $0.66 \pm 0.16$ & & & \\
\hline & & End-Ex & $3.47 \pm 0.31$ & $3.47 \pm 0.37$ & & & \\
\hline \multirow{4}{*}{$\begin{array}{c}\dot{V}_{\mathrm{E}} / \dot{V} \mathrm{CO}_{2}(\mathrm{~L} \cdot \mathrm{min}- \\
\mathbf{1})\end{array}$} & \multirow{2}{*}{$\mathrm{IH}$} & Rest & $26.48 \pm 4.00$ & $29.57 \pm 263$ & $\dagger$ & $29.69 \pm 2.20$ & $\dagger^{\# *}$ \\
\hline & & End-Ex & $40.54 \pm 4.57$ & $42.02 \pm 6.33$ & & $47.44 \pm 3.34$ & $*$ \\
\hline & \multirow{2}{*}{$\mathrm{CON}$} & Rest & $27.57 \pm 4.64$ & $28.89 \pm 3.02$ & & & \\
\hline & & End-Ex & $43.60 \pm 2.70$ & $43.57 \pm 4.34$ & & & \\
\hline \multirow{4}{*}{$\begin{array}{c}\text { HR } \\
\left(\mathbf{b} \cdot \min ^{-1}\right)\end{array}$} & \multirow{2}{*}{$\mathrm{IH}$} & Rest & $84 \pm 6$ & $80 \pm 3$ & $\dagger$ & $82 \pm 5$ & $\dagger$ \\
\hline & & End-Ex & $177 \pm 6$ & $172 \pm 8$ & & $175 \pm 7$ & \\
\hline & \multirow{2}{*}{$\mathrm{CON}$} & Rest & $84 \pm 9$ & $85 \pm 7$ & & & \\
\hline & & End-Ex & $173 \pm 8$ & $175 \pm 7$ & & & \\
\hline \multirow{2}{*}{ RPE } & $\mathrm{IH}$ & End-Ex & $20 \pm 0$ & $17 \pm 2$ & $\dagger^{\# *}$ & $20 \pm 0$ & $\dagger$ \\
\hline & $\mathrm{CON}$ & End-Ex & $20 \pm 0$ & $20 \pm 0$ & & & \\
\hline \multirow{2}{*}{ Dyspnoea } & $\mathrm{IH}$ & End-Ex & $10 \pm 0$ & $6 \pm 2$ & $t^{* * *}$ & $10 \pm 0$ & $\dagger$ \\
\hline & $\mathrm{CON}$ & End-Ex & $10 \pm 0$ & $10 \pm 0$ & & & \\
\hline
\end{tabular}

$\dot{V}_{\mathrm{E}}$, minute ventilation; $\mathrm{P}_{\mathrm{ET}} \mathrm{CO}_{2}$, partial pressure of end-tidal carbon dioxide; $\dot{V} \mathrm{O}_{2}$, oxygen uptake, $\dot{V} \mathrm{CO}_{2}$, carbon dioxide production; $\dot{V}_{\mathrm{E}} / \dot{V} \mathrm{CO}_{2}$, ventilatory equivalent for carbon dioxide; HR, heart rate; RPE, rating of perceived

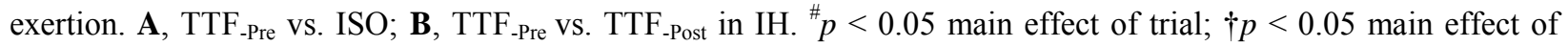
time, $* p<0.05$ vs. TTF $^{1}$. 


\section{LIST OF SUPPLEMENTAL DIGITAL CONTENT}

Supplemental Digital Content 1.doc-Haematological measures before and 72-h after an intervention of intermittent hypoxia $(\mathrm{IH})$ or control protocol in normoxia 


\section{Supplemental Digital Content}

Haematological measures before and 72-h after an intervention of intermittent hypoxia (IH) or control protocol in normoxia.

\begin{tabular}{|c|c|c|c|c|c|c|}
\hline & & Pre-Intervention & Post-Intervention & $f_{(1,7)}$ & $p$ & $n p^{2}$ \\
\hline \multirow{2}{*}{ Total Haemoglobin Mass (g) } & $\mathrm{IH}$ & $875 \pm 155$ & $880 \pm 112$ & \multirow{2}{*}{0.03} & \multirow{2}{*}{0.857} & \multirow{2}{*}{0.03} \\
\hline & Control & $860 \pm 117$ & $860 \pm 104$ & & & \\
\hline \multirow{2}{*}{ Plasma Volume (mL) } & $\mathrm{IH}$ & $937 \pm 259$ & $899 \pm 188$ & \multirow{2}{*}{0.14} & \multirow{2}{*}{0.580} & \multirow{2}{*}{0.13} \\
\hline & Control & $922 \pm 127$ & $914 \pm 97$ & & & \\
\hline \multirow{2}{*}{ Blood Volume (mL) } & $\mathrm{IH}$ & $1812 \pm 400$ & $1778 \pm 1281$ & \multirow{2}{*}{0.18} & \multirow{2}{*}{0.683} & \multirow{2}{*}{0.01} \\
\hline & Control & $1781 \pm 244$ & $1774 \pm 165$ & & & \\
\hline \multirow{2}{*}{$\begin{array}{l}\text { Haemoglobin Concentration } \\
\qquad\left(\mathrm{g} \cdot \mathrm{dL}^{-1}\right)\end{array}$} & $\mathrm{IH}$ & $16.5 \pm 1.0$ & $16.5 \pm 1.0$ & \multirow{2}{*}{0.51} & \multirow{2}{*}{0.490} & \multirow{2}{*}{0.04} \\
\hline & Control & $15.0 \pm 0.1$ & $15.4 \pm 0.5$ & & & \\
\hline
\end{tabular}

$\mathrm{IH}$, intermittent hypoxia. IH, $n=9$; control, $n=4$. ANOVA result is provided for the interaction of trial (pre- and post-intervention) x group (IH vs. control). 